\title{
Retraction Note to: Mouse models of intestinal inflammation and cancer
}

\author{
Aya M. Westbrook ${ }^{1,2} \cdot$ Akos Szakmary $^{3} \cdot$ Robert H. Schiestl ${ }^{1,2}$
}

Published online: 28 September 2018

๑) Springer-Verlag GmbH Germany, part of Springer Nature 2018

\section{Retraction to: Arch Toxicol (2016) 90:2109-2130} https://doi.org/10.1007/s00204-016-1747-2

The authors are retracting this article (Westbrook et al. 2016) because it has been published previously (Westbrook et al. 2010). Robert H. Schiestl and Aya M. Westbrook agree with this retraction. Akos Szakmary has not responded to any correspondence about this retraction.

\section{References}

Westbrook AM, Szakmary A, Schiestl RH (2010) Mechanisms of intestinal inflammation and development of associated cancers: lessons learned from mouse models. Mutat Res 705(1):40-59

Westbrook AM, Szakmary A, Schiestl RH (2016) Mouse models of intestinal inflammation and cancer. Arch Toxicol 90(9):2109-2130

The original article can be found online at https://doi.org/10.1007/ s00204-016-1747-2.

\section{Robert H. Schiestl}

Rschiestl@mednet.ucla.edu

1 Molecular Toxicology Interdepartmental Program, UCLA School of Medicine and School of Public Health, University of California at Los Angeles, Los Angeles, CA 90095, USA

2 Department of Pathology and Lab Medicine, UCLA School of Medicine and School of Public Health, University of California at Los Angeles, 650 Charles E. Young Drive South, 71-295 CHS, Los Angeles, CA 90095, USA

3 Institute for Cancer Research, Medical University of Vienna, Vienna, Austria 